\title{
FEATURES OF LABORATORY MONITORING FOR EARLY DETECTION OF COLONIC ANASTOMOSIS LEAK
}

\author{
Shpak V.V. ${ }^{2}$, Pozdnyakov A.A. ${ }^{1}$, Cherdantsev D.V. ${ }^{1}$, Popov A.E. ${ }^{1}$ Filistovich V.G. ${ }^{1}$
}

${ }^{1}$ Krasnoyarsk State Medical University n.a. Professor V.F. Voyno-Yasenetsky, Krasnoyarsk, e-mail: artem.pozdnyakov.doc@gmail.com;

${ }^{2}$ Krasnoyarsk Regional Clinical Oncology Center.n.a. A.I. Kryzhanovskiy, Krasnoyarsk, e-mail: shpakvv72@mail.ru

Aims.

The work was aimed at identifying the characteristics of the dynamics of changes in laboratory parameters in patients with colonic anastomosis leak for early diagnosis of postoperative complications.

Materials and methods.

The dynamics of laboratory parameters of blood and peritoneal effusion on the first to seventh postoperative day was studied in 102 patients operated on for colorectal cancer. All patients had complete resection of the colon with tumour; surgery was ended with interintestinal anastomosis. A single-layer continuous blanket anastomosis and machine stapling anastomosis were used. The following laboratory parameters were investigated: $\mathrm{C}$-reactive protein, pyruvate and lactate concentration, $\mathrm{pH}$ of peritoneal effusion and leukocytic index of intoxication.

Results.

The development of leaking intestinal anastomosis was detected in $8.8 \%$. The most clinically significant indicators for early diagnosis of anastomosis leak were leukocytic index of intoxication, C-reactive protein, $\mathrm{pH}$ of effusion in the abdominal cavity and the ratio of the effusion lactate to blood plasma lactate.

Conclusions.

The combined use of these parameters allows suspecting with a high degree of reliability of the leak of intestinal anastomosis as early as on the third day after surgery.

Keywords: $\quad$ postoperative complications, leak of colonic anastomosis, laboratory diagnostics.

\section{INTRODUCTION.}

Intestinal anastomotic dehiscence (IAD) is one of the severe complications in colorectal surgery that is associated with the increase in the lethality rate and the duration of hospitalization [1; 2]. During recent decades, new technological methods of anastomosis placement have been developed. However, this has not led to a decrease in the rate of IAD [3]. According to the published data, the rate of IAD varies from 1 to $19 \%$ and depends on the type of applied anastomosis. Thus, in cases with ileocolonic anastomosis, the rate of IAD is registered in 1-8\% of cases, coloenteric anastomosis - in 2-3\%, ileorectal anastomosis - in 3-7\%, in cases with colorectal or coloanal anastomosis, this rate is the highest and reaches 19\% [4; 5]. A high rate of IAD was observed not only in local studies focused on the results of cases with low colorectal anastomosis but also in well planned randomized populational studies [6;7].

A significant amount of features are considered to be risk factors for colon anastomosis dehiscence. They include the male sex, comorbid diseases, the functional status of organs and systems, the nutritional status, bad habits (smoking, alcohol consumption), immune suppression, neo-adjuvant chemo- and radiotherapy, diverticulitis, the stage of the tumor process, low colorectal anastomosis, the duration of surgery, intraoperative hemorrhage or perioperative hemotransfusion $[2 ; 4 ; 8]$. It should be mentioned that some risk factors for IAD cannot be corrected in inpatient conditions and risk factors that can be potentially controlled are hard to be fixed by a surgeon [2; 4].

Emergency intervention on the colon is an independent risk factor for IAD. At the same time, the formation of the discharging stoma decreases the rate of the development of clinically significant IDA complications, especially, in patients with low anterior resection [6]. 
Many authors highlight that the development of IAD is associated with the worsening of oncological results and 5-year overall survival in patients with colon cancer. In particular, IAD decreases overall survival and increases the rate of tumor recurrence regardless of the stage of the malignant process [10]. According to the published data, the rate of local tumor recurrence varies from 0.5 to $30 \%$ depending on the methods of diagnostics and the degree of IAD severity [11]. The research group that studied rectal cancer defined three levels of IAD severity: level A - IAD that does not require active therapeutic measures, level $\mathrm{B}$ - IAD that requires active therapeutic measures without relaparotomy, and level C - IAD that requires relaparotomy [12].

Clinical and oncological results of the treatment of colorectal cancer in patients with IAD directly depend on the stage of diagnostics of this complication. Early diagnostics of IAD plays a crucial role in the prevention of severe septic complications. The anastomotic dehiscence is rarely diagnosed before the $5^{\text {th }}$ day after the surgery, usually, it is revealed on the $4^{\text {th }}-8^{\text {th }}$ day after the surgery $[3 ; 9 ; 13]$. It is explained by the fact that the clinical picture is not always manifested as peritonitis or intraabdominal and can look like fever, intestinal obstruction or even diarrhea. However, some symptoms of anastomotic dehiscence, often non-specific, can manifest earlier [13]. The diagnostics of anastomotic dehiscence at the early stages allows avoiding numerous complications and decreasing the lethality rate [2]. In clinical practice, the gold standard of anastomotic dehiscence diagnostics is computed tomography, especially, with intravenous and intraintestinal contrasting [3; 9].

Presently, there are no known specific markers of anastomotic dehiscence in colorectal surgery. One of the early markers of anastomotic dehiscence is C-reactive protein (CRP). Its level increases by the $3^{\text {rd }}-4^{\text {th }}$ day after the surgery, which is associated with the systemic inflammatory reaction that develops as a result of intraabdominal septic complications. Still, the sensitivity and specificity of the test remain doubtful and the reference values range from 150 to $250 \mathrm{mg} / \mathrm{L}$ [13-15].

Several studies demonstrated that a prognostic significant level of CRP is $180 \mathrm{mg} / \mathrm{L}$ and higher. This provides grounds for a high prognostic significance of CRP in patients with anastomosis [16]. At the same time, the results of some meta-analyses showed that the concentration of CRP on the $3^{\text {rd }}-5^{\text {th }}$ day after the surgery is a useful negative prognostic test and not a good positive predictor $[1 ; 17]$. Probably, this is associated with the fact that the concentration of CRP in blood samples can be a precise prognostic factor of the lethal outcome caused by any reason [18].

Another direction in the search for IAD predictors is the study of peritoneal exudate for the cytokines IL-6, IL-10, and TNF- $\alpha$. Several studies showed the increase in the levels of these inflammatory mediators within the $1^{\text {st }}$ three days after the surgery in patients with IAD [19]. Apart from cytokines, peritoneal exudate was used for the study of the concentration of biochemical markers that indicate tissue hypoxia, like pyruvate and lactate [20;21]. It was proposed to use the $\mathrm{pH}$ level of peritoneal exudate as a criterion of the evaluation of tissue ischemia and the development of inflammatory complications. Several studies demonstrated that a decrease in the $\mathrm{pH}$ 
level to 6.8 on the $3^{\text {rd }}$ day after the surgery could indicate the development of intraabdominal complications, including IAD. The $\mathrm{pH}$ level of the exudate as a predictor of IAD is highly sensitive $(98.7 \%)$ and specific $(94.7 \%)[22]$.

In the present study, the authors analyzed the daily dynamics of the changes in laboratory blood parameters and peritoneal exudate in the post-operative period in patients that underwent radical surgery for malignant neoplasms in the colon with the primary reconstruction of the colon continuity.

Materials and Methods. The study included 111 patients that underwent surgery for malignant neoplasms of the left colon in 2015-2016 in the Coloproctological Department of "Krasnoyarsk Clinical Hospital No. 20 named after I.S. Berzon”. The study was performed prospectively. The analysis did not include patients without anastomosis and with preventive intestinal stomas. All patients underwent midline laparotomy. The study excluded patients with IV stage tumors. All patients included in the study had blood parameters and peritoneal exudate tests on Days 1, 2, 3, 5, and 7 after the surgery.

The study protocol followed guidelines for experimental investigation with human subjects in accordance with the Declaration of Helsinki and was approved by the ethics committee. Written informed consent was obtained from each patient (or official representative) before the study.

In the specified period, patients were tested for the blood content of leucocytes, ESR, the leukocytal intoxication index (Kal-Kalif, 1941), C-reactive protein, and lactate. The peritoneal exudate was used for the estimation of $\mathrm{pH}$ and lactate.

The comparative analysis of the specified parameters was performed in patients with an uncomplicated post-operative period and patients with IAD. The destitution of patients into groups was made retrospectively based on the clinically verified IAD in the post-operative period.

Statistical analysis included testing for the normality of distribution performed with the Kholmogorov-Smirnov test. The comparison of average values in the groups was performed with the Mann-Whitney U-test.

RESULTS. During the specified period, 111 patients met the study entry criteria. The group of patients that did not have complications in the post-operative period included 102 patients: 52 males $(51 \%)$ and 50 females $50(49 \%)$. The average age of participants was $65 \pm 10.5$ years old (Table 1). Malignant neoplasm in the colon was localized in c. sigmoideum in 78 patients (76.5\%) and c. descendens - in 24 patients $(23.5 \%)$. By the stage of the tumor process, the patients were divided into three groups: 15 patients with stage I (14.7\%), 35 patients with stage II (34.3\%), 52 patients with stage III (51.0\%) (according to TNM classification).

Intestinal anastomotic dehiscence was registered in 9 patients $(8.1 \%)$ that formed the group of patients with IAD. The rate of the development of IAD did not depend on the localization of the tumor: in 6 patients - after the resection of the sigmoid colon (7.6\%) and in 3 patients - after the left-sided hemicolectomy $(12.5 \%)\left(\chi^{2}-0.49, \mathrm{p}>0.05\right)$. Male patients prevailed in this group (6 patients, $67 \%$ ). In the majority of cases, the tumor process of stage III was diagnosed ( 7 patients, $78 \%)$. 
Table 1. Characteristics of patients included in the study

\begin{tabular}{|c|c|c|c|}
\hline & $\begin{array}{l}\text { Without } \\
\text { complications, } \mathrm{n} \\
(\%)\end{array}$ & $\begin{array}{l}\text { Anastomotic } \\
\text { dehiscence, } \mathrm{n}(\%)\end{array}$ & $\mathrm{p}^{*}$ \\
\hline $\begin{array}{ll}\text { Sex } & \\
& \text { male } \\
& \text { female }\end{array}$ & $\begin{array}{l}52(51 \%) \\
50(49 \%)\end{array}$ & $\begin{array}{l}6(67 \%) \\
3(33 \%)\end{array}$ & $>0.05$ \\
\hline $\begin{array}{l}\text { Age } \\
\quad \leq 60 \\
\\
>60\end{array}$ & $\begin{array}{l}43(42 \%) \\
58(58 \%)\end{array}$ & $\begin{array}{l}4(44 \%) \\
5(56 \%)\end{array}$ & $>0.05$ \\
\hline $\begin{array}{l}\text { Tumor localization } \\
\text { c. descendens } \\
\text { c. sigmoideum }\end{array}$ & $\begin{array}{l}78(76.5 \%) \\
24(23.5 \%)\end{array}$ & $\begin{array}{c}6(7.6 \%) \\
3(12.5 \%)\end{array}$ & $>0.05$ \\
\hline $\begin{array}{c}\text { Process stage } \\
\text { stage I } \\
\text { stage II } \\
\text { stage III }\end{array}$ & $\begin{array}{l}15(14.7 \%) \\
35(34.3 \%) \\
52(51.0 \%)\end{array}$ & $\begin{array}{l}0(0.0 \%) \\
2(22 \%) \\
7(78 \%)\end{array}$ & $>0.05$ \\
\hline
\end{tabular}

The analysis of the hematological parameters revealed clinically significant results in the dynamics of the levels of leukocytosis, ESR, and the leukocytal intoxication index (LII).

Significant differences in the parameters of leukocytosis and LII between the groups of patients without complications (NC) in the post-operative period and patients with IAD begin to manifest from Day 3 after the surgery. The dynamics of ESR is lower both in the dynamics of negative changes and during the improvement of the patient's condition. First significant differences in ESR begin to be registered on Day 5 after the surgery (Figure 1). There were no significant changes in the dynamics of biochemical parameters in patients with IAD. The only exception was the level of C-reactive protein. Besides, considering the role of tissue ischemia in the development of IAD, the authors additionally studied the levels of plasma lactate.

It should be mentioned that significant differences in the levels of CRP between the groups of patients with IAD and without complications start to be registered from Day 2 after the surgery, while the levels of lactate in blood plasma start to differ from Day 5 after the surgery (Figure 2). 


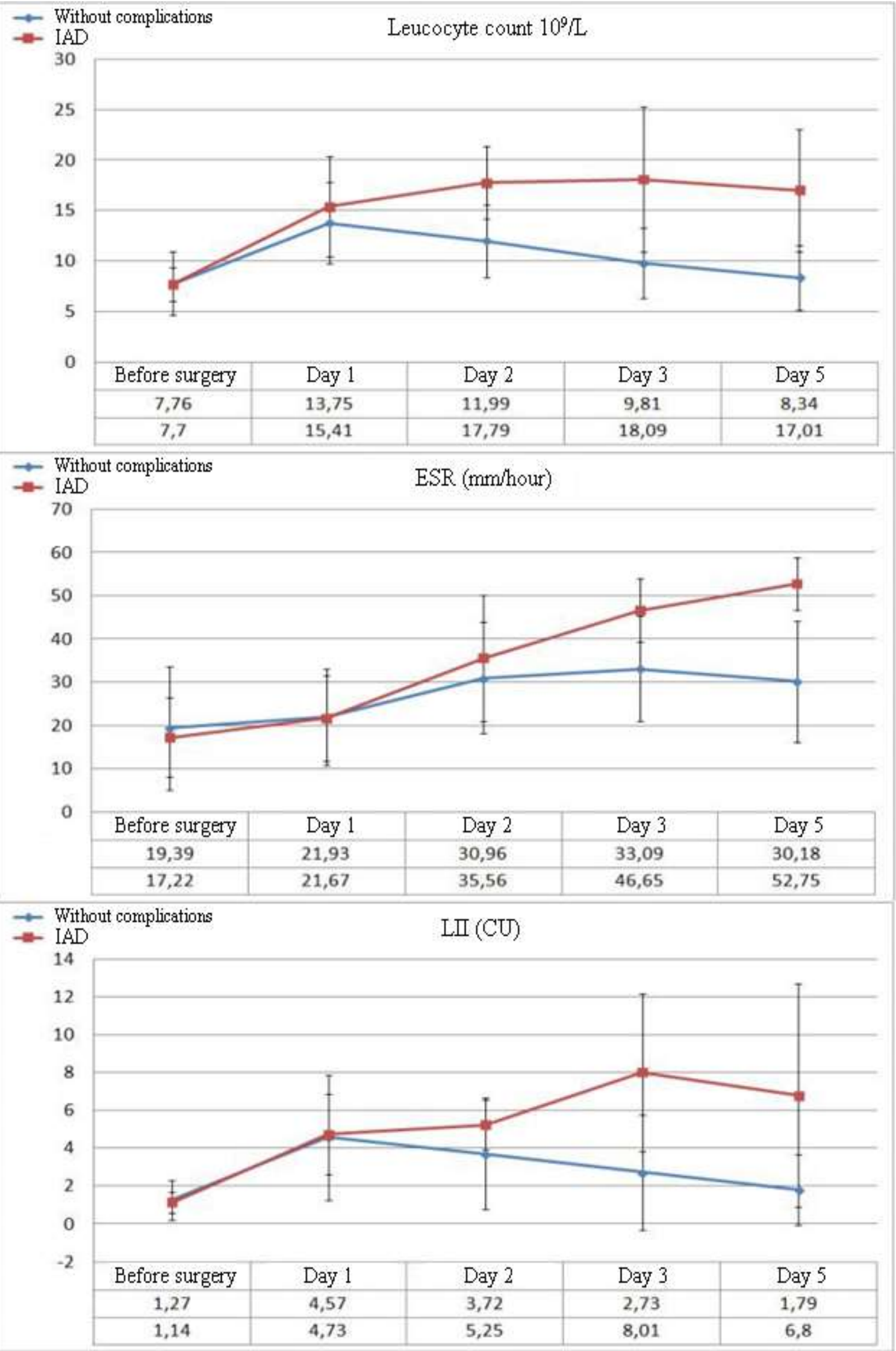

Figure 1. Dynamics of the levels of leukocytosis, ESR, and LII in the post-operational period in patients without complications and with development of IAD 


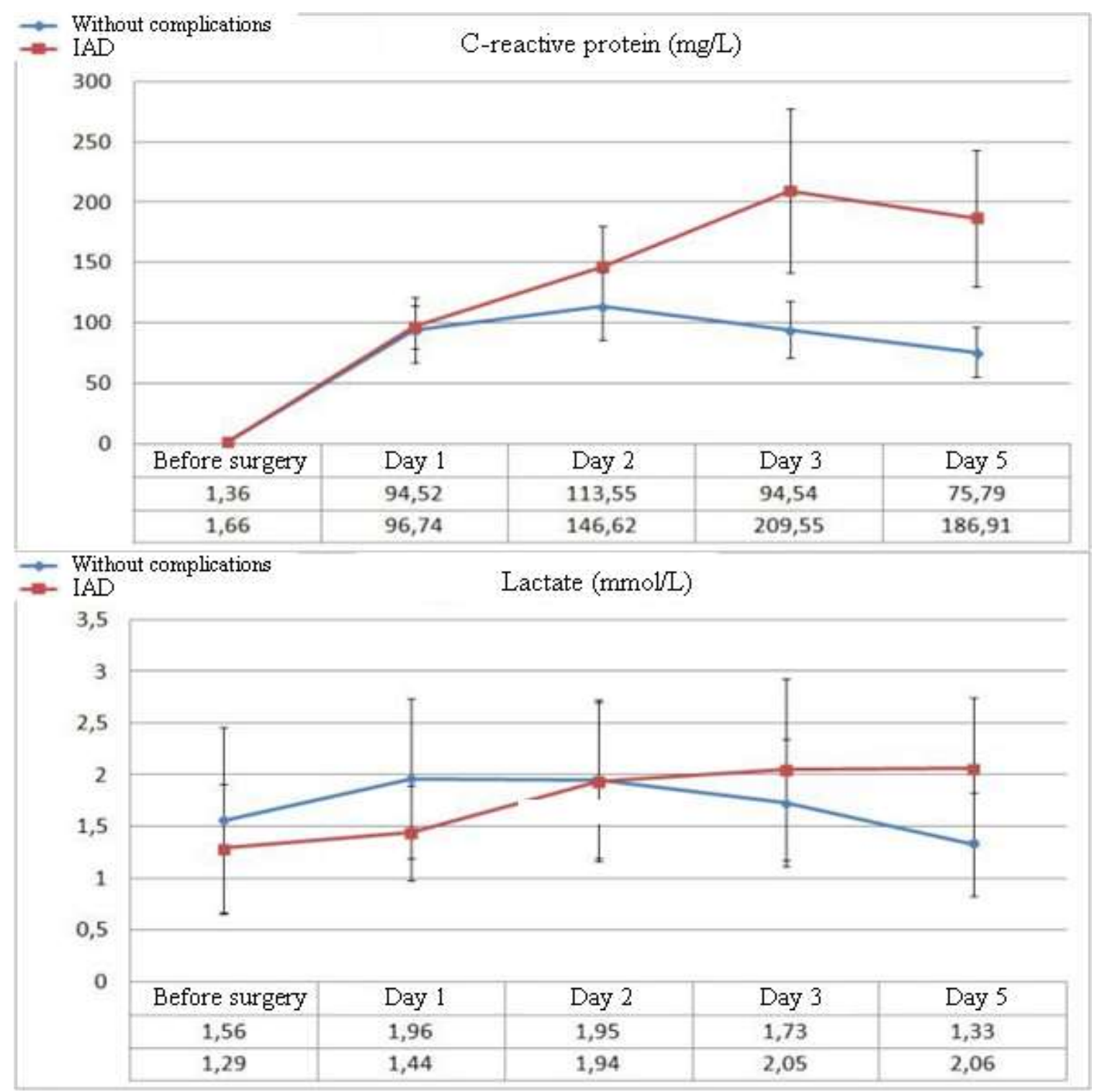

Figure 2. Dynamics of the levels of CRP and plasma lactates in the post-operative period

The dynamics of biochemical parameters in the abdominal exudate demonstrates significant differences in the levels of lactate and $\mathrm{pH}$ at the early stages of the development of complications (Figure 3). A significant decrease in the levels of exudate $\mathrm{pH}$ to $6.8 \pm 0.51(\mathrm{p}=0.023)$ in patients with IAD was observed from Day 2 after the surgery. Further, the levels of $\mathrm{pH}$ did not exceed this value. In patients without complications after the surgery, this parameter did not decrease below $7.14 \pm 0.24$. 


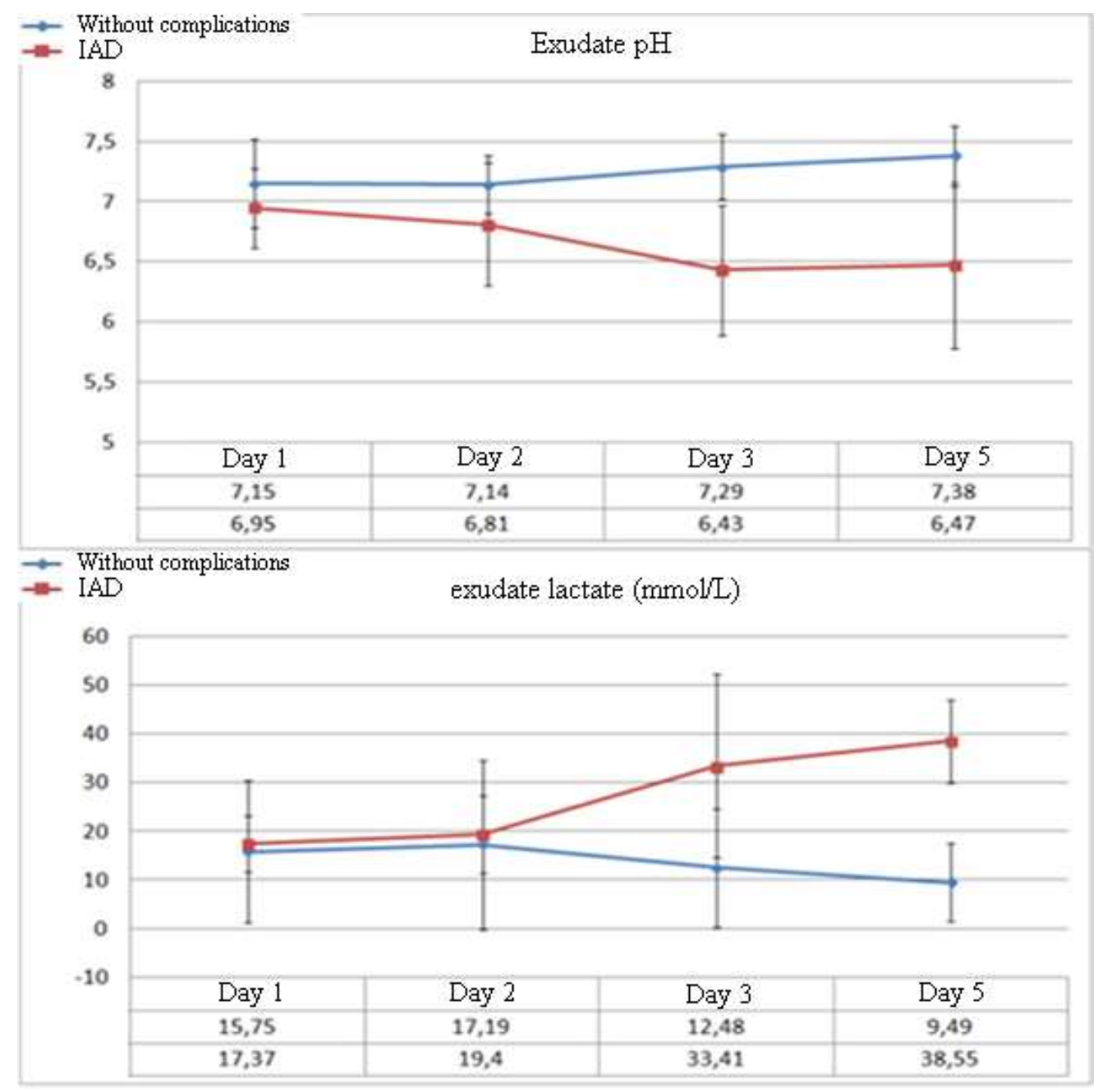

Figure 3. Dynamics of the levels of abdominal exudate $\mathrm{pH}$ and lactate in the post-operative period

Often, the analysis of the mean values did not allow surgeons to choose certain tactics for the treatment of an individual patient. Even in some patients without complications in the postoperative period, the values of some parameters (for example, CRP) were registered at the levels typical for a complicated post-operative period. For the personification of the diagnostic approach, the authors analyzed the dynamics of the changes in the relative values of CRP and lactate levels. kCRP was calculated as the ratio of the current level of CRP to the level of CRP registered on Day 1 after the surgery. kLac was calculated as the ratio of exudate lactate to plasma lactate. 


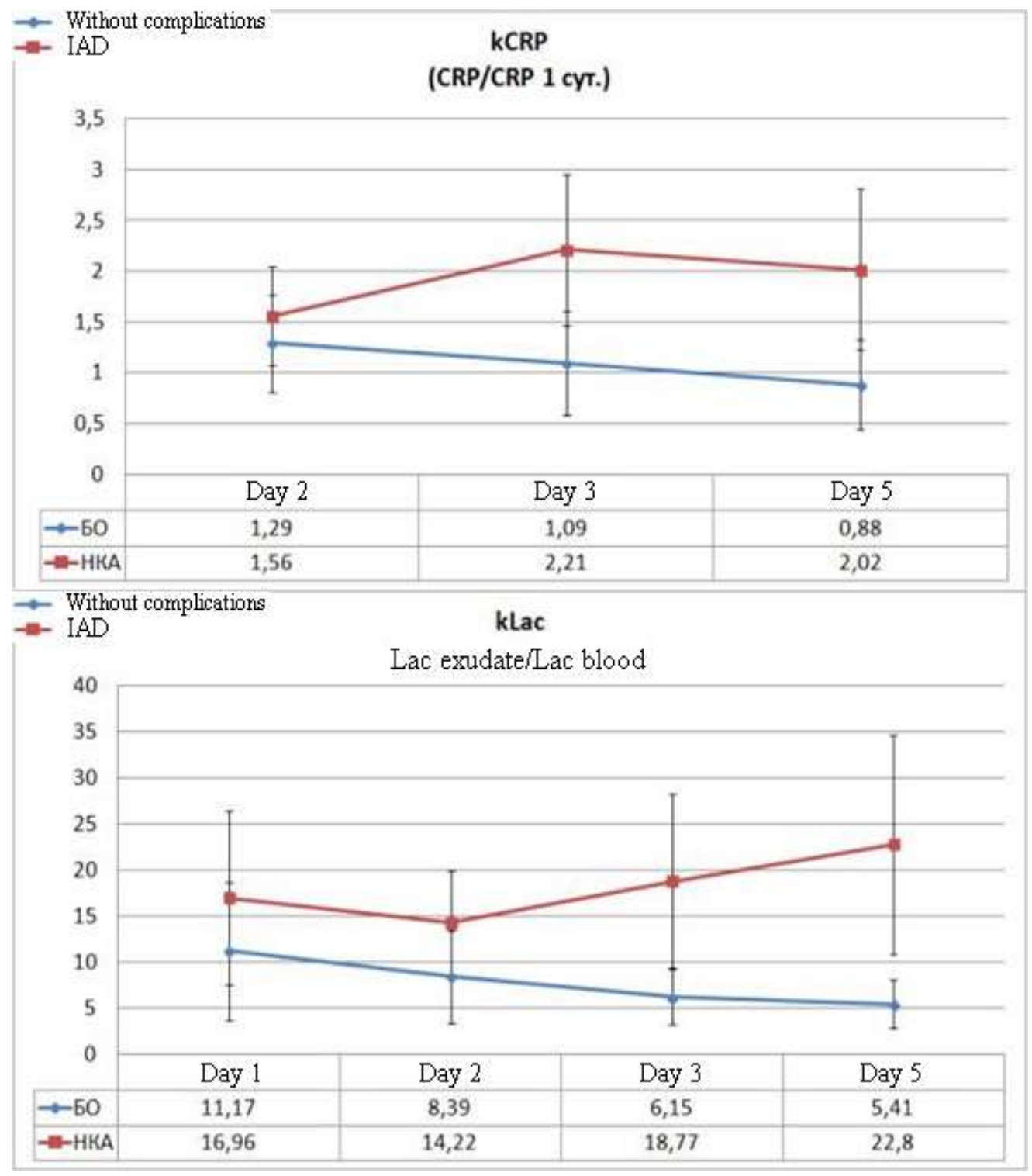

Figure 4. Dynamics of the calculated coefficients in the post-operative period in patients without complications and with the development of IAD

The analysis of the daily dynamics of the specified coefficients and the comparison of their levels between the groups indicate the appearance of significant differences on Day 2 after the surgery. On Day 3, these differences become highly significant (Figure 4). Thus, the level of kCRP in patients with IAD exceeds the control parameter on Day 2 by $21 \%(\mathrm{p}=0.016)$, and from Day 3, this difference starts to exceed it by $100 \%$ ( $\mathrm{p}<0.001)$. The difference in kLac levels indicates highly significant differences from Day 2 of the observation when the difference with the control reaches 69\% $(\mathrm{p}=0.002)$. On Day 3, this parameter exceeds the control by 3 times $(\mathrm{p}<0.001)$ and the tendency toward the increase remains.

CONCLUSIONS. Early diagnostics of post-operative complications is a complex clinical, laboratory, and instrumental search for a combination of "minor" signs of the developed pathological process, clinically not manifested yet in full. The performed analysis of the dynamics of the levels of hematological and biochemical plasma markers and biochemical parameters of peritoneal exudate provides grounds for the identification of the levels of leucocytes, LII, CRP, and abdominal exudate 
$\mathrm{pH}$ as a group of laboratory predictors of IAD that allow the doctors to suspect IAD on Day 3 after the surgery. In combination with the calculated values of kCRP and kLac, they increase the diagnostic value of the proposed set of tests in the early diagnostics of IAD.

\section{FINANCIAL SUPPORT AND SPONSORSHIP}

Nil.

\section{CONFLICTS OF INTEREST}

The authors declare no conflict of interest

SUPPLEMENTARY DATA (DOI)

\section{REFERENCES}

1. Krarup P.M., Nordholm-Carstensen A., Jorgensen L.N. et al. Anastomotic leak increases distant recurrence and long-term mortality after curative resection for colonic cancer: a nationwide cohort study. Annals of Surgery, 2014, vol. 259, no 5, pp. 930-938, doi 10.1097/sla.0b013e3182a6f2fc3.

2. M. Frasson, Flor- Lorente B., Rodríguez J.L. et al. Risk factors for anastomotic leak after colon resection for cancer: multivariate analysis and nomogram from a multicentric, prospective, national study with 3193 patients. Annals of Surgery, 2015, vol. 262, no 2, pp. 321-330, doi 10.1097/sla.0000000000000973.

3. Platell C., Barwood N., Dorfmann G. et al. The incidence of anastomotic leaks in patients undergoing colorectal surgery. Colorectal Disease, 2007, vol. 9, no 1, pp. 71-79, doi 10.1111/j.14631318.2006.01002.x.

4. McDermott F.D., Heeney A., Kelly M.E. et al. Systematic review of preoperative, intraoperative and postoperative risk factors for colorectal anastomotic leaks. British Journal of Surgery, 2015, vol. 102, no 5, pp. 462-479, doi 10.1002/bjs.9697.

5. Pinkney D.T., Battersby N.J., Bhangu A. et al. The relationship between method of anastomosis and anastomotic failure after right hemicolectomy and ileo-caecal resection: an international snapshot audit. Colorectal Disease, 2017, vol. 38, no 1, pp. 42-49.

6. Matthiessen P., Hallbook O., Rutegard J. et al. Defunctioning stoma reduces symptomatic anastomotic leakage after low anterior resection of the rectum for cancer: a randomized multicenter trial. Annals of Surgery, 2007, vol. 246, no 2, pp. 207-214, doi 10.1097/sla.0b013e3180603024.

7. Matsubara N., Miyata H., Gotoh M. et al. Mortality after common rectal surgery in Japan: a study on low anterior resection from a newly established nationwide large-scale clinical database. Diseases of the Colon and Rectum, 2014, vol. 57, no 9, pp. 1075-1081, doi 10.1097/dcr.0000000000000176.

8. Chadi S.A., Fingerhut A., Berho M. et al. Emerging trends in the etiology, prevention, and treatment of gastrointestinal anastomotic leakage. Journal of Gastrointestinal Surgery, 2016, vol. 20, no 12, pp. 2035-2051, doi 10.1007/s11605-016-3255-3. 
9. Law W.L., Choi H.K., Lee Y.M. et al. The impact of postoperative complications on long-term outcomes following curative resection for colorectal cancer. Annals of Surgical Oncology, 2007, vol. 14, no 9, pp. 2559-2566, doi 10.1245/s10434-007-9434-4

10. Snijders H.S., Wouters M.W., van Leersum N.J. et al. Meta-analysis of the risk for anastomotic leakage, the postoperative mortality caused by leakage in relation to the overall postoperative mortality. Journal of Surgical Oncology, 2012, vol. 38, no 11, pp. 1013-1019, 10.1016/j.ejso.2012.07.111.

11. Zheqin L., Lynch N., Craig A. et al. Anastomotic leaks after restorative resections for rectal cancer compromise cancer outcomes and survival. Diseases of the Colon \& Rectum, 2016, vol. 59, no 3, pp. 236-244, doi 10.1097/dcr.0000000000000554.

12. Rahbari N.N., Weitz J., Hohenberger W. et al. Definition and grading of anastomotic leakage following anterior resection of the rectum: a proposal by the International Study Group of Rectal Cancer. Surgery, 2010, vol. 147, no 3, pp. 339-351, doi 10.1016/j.surg.2009.10.012.

13. Alves A., Panis Y., Trancart D. et al. Factors associated with clinically significant anastomotic leakage after large bowel resection: multivariate analysis of 707 patients. World Journal of Surgery, 2002, vol. 26, no 4, pp. 499-502, doi 10.1007/s00268-001-0256-4.

14. Kolisnechenko A.P., Mosiakin N.A., Rasponin Iu.S. et al. Informativeness of the various biochemical markers of sepsis: literary and own data [Informativnost' razlichnykh biokhimicheskikh markerov sepsisa: literaturnye i sobstvennye dannye]. Siberian Medical Review - Sibirskoe meditsinskoe obozrenie, 2015, no. 4, pp. 11-17, doi 10.20333/25000136-2015-4-11-17.

15. Adamina M., Steffen T., Tarantino I. et al. Meta-analysis of the predictive value of C-reactive protein for infectious complications in abdominal surgery. British Journal of Surgery, 2015, vol. 102, no 6. pp. 590-598, doi 10.1002/bjs.9756.

16. Warschkow R., Tarantino I., Torzewski M. et al. Diagnostic accuracy of C-reactive protein and white blood cell counts in the early detection of inflammatory complications after open resection of colorectal cancer: a retrospective study of 1,187 patients. International Journal of Colorectal Disease, 2011, vol. 26, no 11, pp. 1405-1413, doi 10.1007/s00384-011-1262-0.

17. Singh P.P., Zeng I.S., Srinivasa S. et al. Systematic review and meta-analysis of use of serum Creactive protein levels to predict anastomotic leak after colorectal surgery. British Journal of Surgery, 2014, vol. 101, no 4, pp. 339-346, doi 10.1002/bjs.9354.

18. Proctor M.J., McMillan D.C., Horgan P.G. et al. Systemic inflammation predicts all-cause mortality: a Glasgow inflammation outcome study. PLoS One, 2015, vol. 10, no 3, p. e0116206, doi 10.1371/journal.pone.0116206.

19. Yamamoto T., Umegae S., Matsumoto K. et al. Peritoneal cytokines as early markers of peritonitis following surgery for colorectal carcinoma: a prospective study. Cytokine. 2011, vol. 53, no 2, pp. 239-242, doi 10.1016/j.cyto.2010.10.006.

20. Romashchenko P.N., Maistrenko N.A., Silin N.L. et al. Intraperitoneal microdialysis as a method 
for early detection of postoperative visceral ischemia [Vnutribriushnoi mikrodializ - metodika rannei diagnostiki posleoperatsionnoi vistseral'noi ishemii]. Regional blood circulation and microcirculation - Regionarnoe krovoobrashchenie i mikrotsirkuliatsiia, 2012, vol. 11, no. 3, pp. 39-44, doi: 10.24884/1682-6655-2012-11-3-39-44

21. Ellebaek Pedersen M., Qvist N., Bisgaard C. et al. Peritoneal microdialysis. Early diagnosis of anastomotic leakage after low anterior resection for rectosigmoid cancer. Scandinavian Journal of Surgery, 2009, vol. 98, no 3, pp. 148-154, doi 10.1177/145749690909800304.

22. Yang L., Huang X.E., Xu L. et al. Acidic pelvic drainage as a predictive factor for anastomotic leakage after surgery for patients with rectal cancer. Asian Pacific Journal of Cancer Prevention, 2013, vol. 14, no 9, pp. 5441-5447, doi 10.7314/apjcp.2013.14.9.5441. 